\title{
Zynamite ${ }^{\circledR}$ (Mangifera indica Leaf Extract) and Caffeine Act in a Synergistic Manner on Electrophysiological Parameters of Rat Central Nervous System
}

\author{
Wilfried Dimpfel ${ }^{1 *}$, Julia Wiebe ${ }^{2}$, Nigel Gericke ${ }^{2}$, Leonie Schombert ${ }^{3}$ \\ ${ }^{1}$ Justus-Liebig-University Giessen c/o NeuroCode AG, Wetzlar, Germany \\ ${ }^{2}$ Nektium S.L., Las Palmas, Spain \\ ${ }^{3}$ NeuroCode AG, Wetzlar, Germany \\ Email: *wilfried.dimpfel@pharma.med.uni-giessen.de
}

How to cite this paper: Dimpfel, W., Wiebe, J., Gericke, N. and Schombert, L. (2018) Zynamite ${ }^{\infty}$ (Mangifera indica Leaf Extract) and Caffeine Act in a Synergistic Manner on Electrophysiological Parameters of Rat Central Nervous System. Food and Nutrition Sciences, 9, 502-518. https://doi.org/10.4236/fns.2018.95039

Received: April 5, 2018

Accepted: May 19, 2018

Published: May 22, 2018

Copyright $\odot 2018$ by authors and Scientific Research Publishing Inc. This work is licensed under the Creative Commons Attribution International License (CC BY 4.0).

http://creativecommons.org/licenses/by/4.0/

\begin{abstract}
Zynamite ${ }^{\oplus}$, a special extract from Mangifera indica, exerted stimulatory properties on the central nervous system during a pilot study. The question arose if Zynamite $^{\oplus}$ would have a similar action on the central nervous system as caffeine. Two well established animal models were used: a) quantitation of spectral power of field potentials in the freely moving rat and b) induction of long term potentiation (LTP) in the hippocampus slice preparation ex vivo after one week of daily administration. In the presence of $25 \mathrm{mg} / \mathrm{kg}$ of Zynamite ${ }^{\oplus}$, predominantly alpha2 and beta1 spectral frequencies were attenuated in all brain areas during the first hour after administration. Exactly this pattern of frequency changes had been observed in earlier studies with i.p. administration of caffeine. Discriminant analysis confirmed this similarity by projection of Zynamite ${ }^{\circledast}$ and $0.5 \mathrm{mg} / \mathrm{kg}$ caffeine into close neighborhood and showing identical colours, which points to a similar mechanism of action in this analysis. In addition, when Zynamite ${ }^{\oplus}$ was combined with very low doses of caffeine synergistic effects were observed. Since alpha2 waves are under the control of dopamine, activation of this neurotransmitter system might be responsible for the stimulating property of Zynamite ${ }^{\oplus}$. These results are corroborated by the results from the ex vivo study using the hippocampus slice in vitro to follow changes in excitability in the presence of $0.5 \mathrm{mg} / \mathrm{kg}$ of caffeine, $25 \mathrm{mg} / \mathrm{kg}$ of Zynamite ${ }^{\oplus}$ or their combination in comparison to Placebo after daily administration for one week. Both caffeine and Zynamite ${ }^{\oplus}$ increased LTP. LTP relates to space and time dependent memory. From these studies it is evident that both caffeine and Zynamite ${ }^{\oplus}$ act in similar ways on brain elec-
\end{abstract}


trical activity, and have potential to improve cognitive function. Bioactive compounds of Zynamite ${ }^{\varpi}$ clearly pass the blood brain barrier to act on the central nervous system. Due to the demonstrated similarity of action, Zynamite ${ }^{\circledast}$ has potential as a CNS-activating nutraceutical that could be used to replace caffeine.

\section{Keywords}

Zynamite ${ }^{\oplus}$, Mangifera indica, Caffeine, Rat, Field Potential, Hippocampus Slice, Synergy

\section{Introduction}

Mangifera indica is commonly known as "Mango" and belongs to the family of Anacardiaceae. It was domesticated in India about 2000 BC (Wikipedia). The leaves contain a high amount of Mangiferin, a pharmacologically active hydroxylated xanthone C-glycoside. Extract of the leaves have shown antibiotic properties and have diverse uses in traditional Ayurveda medicine [1].

This investigation deals with Zynamite ${ }^{\oplus}$, a special Mango leaf extract containing $60 \%$ of Mangiferin. Since a recent pilot clinical trial in 16 healthy subjects has shown brain stimulatory activity with no cardiovascular changes, the question arose whether Zynamite ${ }^{\varpi}$ could replace caffeine without the side effects known for intake of high doses of caffeine. The present series of experiments focus on the comparison of the effect of Zynamite ${ }^{\circledR}$, caffeine and a combination thereof to placebo 1) with respect to quantitation of spectral power of field potentials in the freely moving rat and 2) with respect to induction of long term potentiation in the hippocampus slice preparation ex vivo after one week of daily administration.

Recording of field potentials from freely moving rats and their wireless transmission has been used now for more than 30 years [2]. Frequency analysis of signals from four brain regions (frontal cortex, hippocampus, striatum and reticular formation) by Fast Fourier transformation (FFT) allowed to differentiate clinically used drugs with respect to their indication when using linear discriminant analysis [3]. This method has been demonstrated to be able to characterize CNS-active herbal preparations with respect to their potential clinical use [4].

The hippocampal slice preparation is a validated model for direct analysis of interaction of substances with living neuronal tissue [5] [6]. Due to the preservation of the three-dimensional structure of the hippocampal tissue, substance effects on the excitability of pyramidal cells can be studied in a unique manner. The stimulation of Schaffer Collaterals leads to release of glutamate resulting in excitation of the postsynaptic pyramidal cells. The result of the electrical stimulation is recorded as so-called population spike (pop-spike) representing the number of recruited pyramidal cells. An interesting result using this model was for example the demonstration of the ability of memantine, a pharmaceutical 
used in the treatment of dementia, to increase the population spike amplitude in response to single stimuli and theta burst stimulation to increase long term potentiation [7].

\section{Material and Methods}

\subsection{Field Potential Analysis in Freely Moving Rats}

EEG signals were recorded from frontal cortex, hippocampus, striatum and reticular formation of freely moving rats from inside a totally copper shielded room. Signals were wirelessly transmitted by a radio-telemetric system (Rhema Labortechnik, Hofheim, Germany, using 40 Megahertz as carrier frequency) and were amplified and processed as described earlier to give power spectra with a resolution of $0.25 \mathrm{~Hz}$ [8]. In short, after automatic artefact rejection signals were collected in sweeps of $4 \mathrm{~s}$ duration and Fast Fourier transformed using a Hanning window. Sampling frequency was $512 \mathrm{~Hz}$. Four values were averaged to give a final sampling frequency of $128 \mathrm{~Hz}$, well above the Nyquist frequency. The resulting electrical power spectra were divided into 8 specially defined frequency ranges (delta: 1.50 - $4.00 \mathrm{~Hz}$; theta: $4.25-6.75 \mathrm{~Hz}$; alpha1: 7.00 - $9.50 \mathrm{~Hz}$; alpha2: 9.75 - $12.25 \mathrm{~Hz}$; betala: 12.50 - $15.00 \mathrm{~Hz}$; beta1b: 15.25 - $17.75 \mathrm{~Hz}$; beta2: 18.00 $34.25 \mathrm{~Hz}$; gamma: $34.50-81.00 \mathrm{~Hz}$ ). Spectra were averaged in steps of 3 minutes each and displayed on-line. In an off-line procedure spectra were averaged to give longer periods for further analysis and data presentation. All dosages of caffeine and its combination with Zynamite ${ }^{ø}$ were tested by oral acute administration. Dosage of Zynamite was chosen on the base of earlier experiments. Solutions were prepared fresh for each experimental day and administered orally by gavage after 45 minutes of pre-drug Vehicle recording. Vehicle was water. Extracts are listed in Table 1.

Nine adult male Fisher 344 rats (5 months of age and day-night converted, weight about 350 - $400 \mathrm{~g}$, provided by Charles River Laboratories, D-97633, Sulzfeld) remained from a preceding study with allowance from the local legal authority "Regierungspräsidum Giessen" and were used in this experimental series. Animals were day-night reversed $(12 \mathrm{~h} / 12 \mathrm{~h})$. The principles of good laboratory animal care were followed in all trials. Animals were implanted with

Table 1. Test drugs-Listing of experimental extracts and vehicle.

\begin{tabular}{|c|c|c|}
\hline Test drugs & Dose & From \\
\hline Zynamite $^{\bullet}$ & $25 \mathrm{mg} / \mathrm{kg}$ & Nektium Pharma S.L. \\
\hline $\begin{array}{c}\text { Zynamite }^{\bullet}+\text { Caffeine } \\
\text { EP USP Natural Anhydrous }\end{array}$ & $25 \mathrm{mg} / \mathrm{kg}+0.25 \mathrm{mg} / \mathrm{kg}$ & Nektium Pharma S.L. \\
\hline $\begin{array}{c}\text { Zynamite }^{\bullet}+\text { Caffeine } \\
\text { EP USP Natural Anhydrous }\end{array}$ & $25 \mathrm{mg} / \mathrm{kg}+0.50 \mathrm{mg} / \mathrm{kg}$ & Nektium Pharma S.L. \\
\hline Caffeine EP USP Natural Anhydrous & $0.5 \mathrm{mg} / \mathrm{kg}$ & Nektium Pharma S.L. \\
\hline VEHICLE $0.9 \% \mathrm{NaCl}$ & $1.0 \mathrm{ml} / \mathrm{kg}$ & Braun Melsungen \\
\hline
\end{tabular}


electrodes into the brain and were given two weeks for recovery from surgery. After this, the wireless transmitter was plugged in for adaptation and control experiments. Unfortunately, 3 animals dropped the implant after performance of the placebo series. After testing the two combinations one further animal dropped the implant thus allowing to test the final single dose of caffeine in only 5 animals. During the recording rats were not restricted and could move freely but did not have food available (chewing would have produced too many artefacts).

Rats were implanted as reported earlier [8]. A crossover design with at least three days of drug holidays in between the administrations was used. Controls were performed by oral administration of $1.0 \mathrm{ml} / \mathrm{kg}$ of vehicle $(0.9 \% \mathrm{NaCl})$ and the mixture Zynamite ${ }^{\oplus}(25 \mathrm{mg} / \mathrm{kg})$ and Caffeine $(0.25$ and $0.50 \mathrm{mg} / \mathrm{kg})$ as well as Caffeine $(0.50 \mathrm{mg} / \mathrm{kg})$. Data were averaged from 5 - 9 animals. Data are expressed as mean values \pm S.E.M. Statistics were calculated by means of the Wilcoxon, Mann, Whitney U-test. The animals were dosed orally at a constant volume of $1.0 \mathrm{ml} / \mathrm{kg}$ per $\mathrm{kg}$ body weight. The dosage administered to each animal was determined every day by the weight of that animal at the time of administration. Wilcoxon, Mann, Whitney U-test was used throughout all experimental data for comparison to results obtained by vehicle administration at the particular timing.

\subsection{Ex Vivo Analysis of Population Spikes in the Hippocampal Slice Preparation}

Hippocampus slices were prepared as reported earlier [8]. In short, after daily administration of trial medication for one week 4 animals were sacrificed under deep anesthesia and the hippocampus was quickly taken out and chopped by a vibrating razor blade to give 6 slices of about $400 \mu$ thickness per animal. After adaptation to artificial cerebrospinal fluid for one hour, slices were transferred to an incubation chamber [9] and superfused with cerebrospinal fluid at $35^{\circ} \mathrm{C}$ [10]. Stimulation of the Schaffer Collaterals by single stimuli or theta burst stimuli resulted in the induction of a population spike or long-term potentiation, respectively [5]. Amplitudes of the population spikes were recorded after stimulation every 10 minutes to prevent potentiation mechanisms. Each animal had been treated for one week with each one of the preparations. Slices were taken one day after the last treatment. Excitability of the hippocampus slices was checked after administration of $25 \mathrm{mg} / \mathrm{kg}$ of Zynamite ${ }^{\circledR}$, a combination with 0.5 $\mathrm{mg} / \mathrm{kg}$ of caffeine and $0.5 \mathrm{mg} / \mathrm{kg}$ of caffeine alone. Rats were treated with each of the preparations daily for one week before the hippocampus was taken out at the next day. An example of the amplitude of the population spike after single shock stimulation and theta burst stimulation is given in Figure 1 for the animal treated with placebo (upper part of the image) and the combination of Zynamite ${ }^{\circledast}$ with caffeine (lower part of the image). Stimulation of the Schaffer Collaterals was performed only every 10 minutes in order to prevent physiological potentiation mechanisms. 

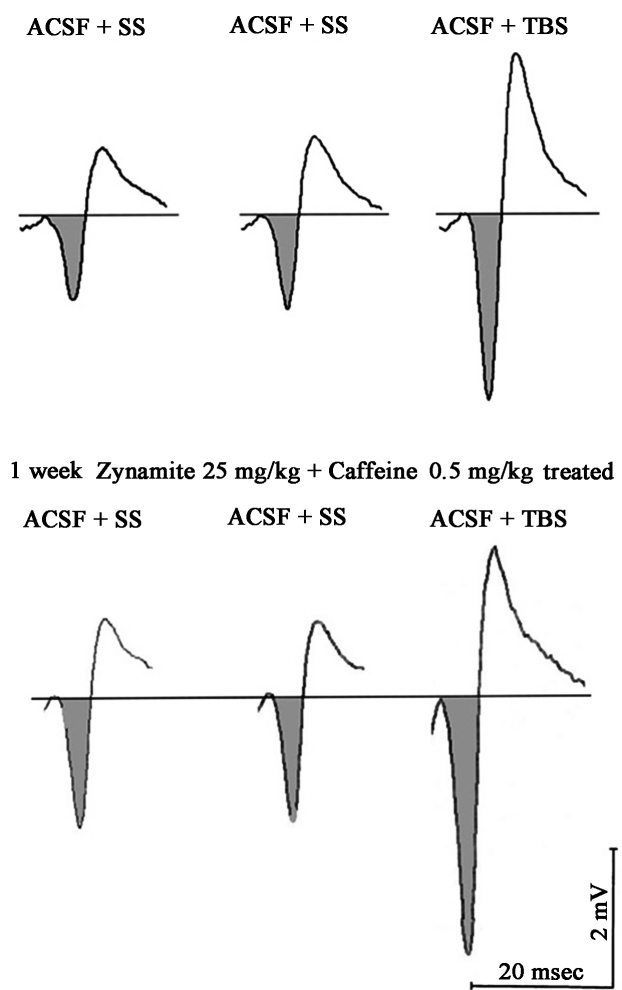

Figure 1. Documentation of original signals (one slice) showing the effects of using single stimuli (SS) or theta burst stimulation (TBS) in the presence of artificial cerebro-spinal fluid (ASCF), Placebo $1 \mathrm{ml} / \mathrm{kg}$ or combination from Zynamite $^{\circledast}(25 \mathrm{mg} / \mathrm{kg})$ and Caffeine $(0.5 \mathrm{mg} / \mathrm{kg})$. The amplitude is calculated from baseline to the down reflection of the signal (shadowed). Scales: Time is given in milliseconds (ms), amplitude in millivolts $(\mathrm{mV})$.

\section{Results}

\subsection{Field Potential Analysis}

Oral administration of the vehicle $(0.9 \% \mathrm{NaCl})$ only resulted in very minor changes of spectral power within the four brain areas. During the second and third to the fifth hour tiny decreases of power emerged in the frontal cortex and hippocampus. With respect to gamma power some tiny increases were observed. A complete time course is given in Figure 2.

Oral administration of $25 \mathrm{mg} / \mathrm{kg}$ of Zynamite ${ }^{\circledast}$ resulted in a statistically significant attenuation of all classic frequencies during the first hour after administration. Strongest effects were documented with respect to alpha2 and beta1 spectral frequencies. Mainly frontal cortex and striatum were involved. During the third hour after administration significant increases of delta power were seen $(\mathrm{p}$ $<0.05)$. Within the striatum a non-significant attenuation of alphal and beta power was recognized throughout the whole recording period of 5 hours (Figure 3).

Oral administration of Caffeine $(0.50 \mathrm{mg} / \mathrm{kg})$ resulted in a statistically conspicuous attenuation $(\mathrm{p}<0.1)$ of delta power in the frontal cortex. In the hippocampus statistically significant attenuation of delta, theta and beta power was 


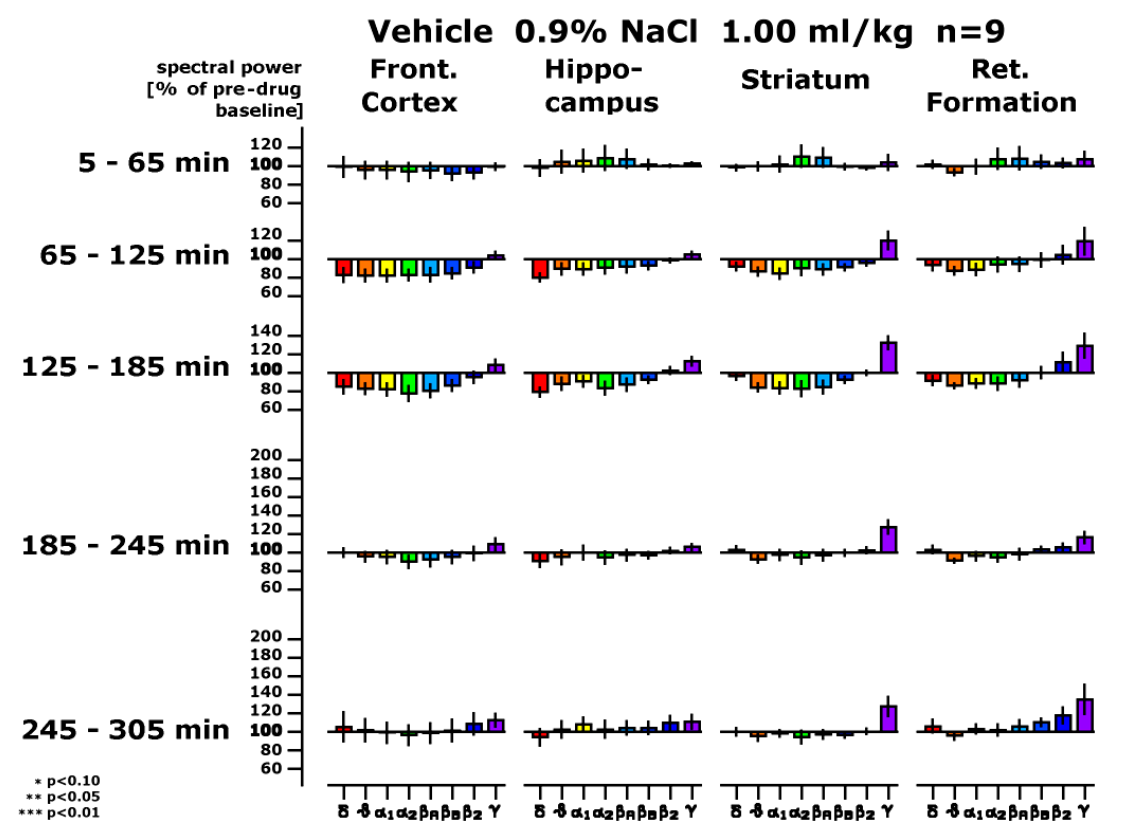

Figure 2. Effect of Vehicle: Time dependence of changes of spectral power (Ordinate) in $\%$ of the $45 \mathrm{~min}$ lasting pre-drug baseline values in four brain regions of the freely moving rat in the presence of Vehicle $(0.9 \% \mathrm{NaCl} 1.0 \mathrm{ml} / \mathrm{kg})$. Frequency ranges are depicted as coloured bar graphs on the abscissa representing delta (red), theta (orange), alpha1 (yellow), alpha2 (green), beta1a (light blue) and betalb (dark blue) and gamma spectral power (violet) from left to right within the four brain areas as mentioned on top of the graph.

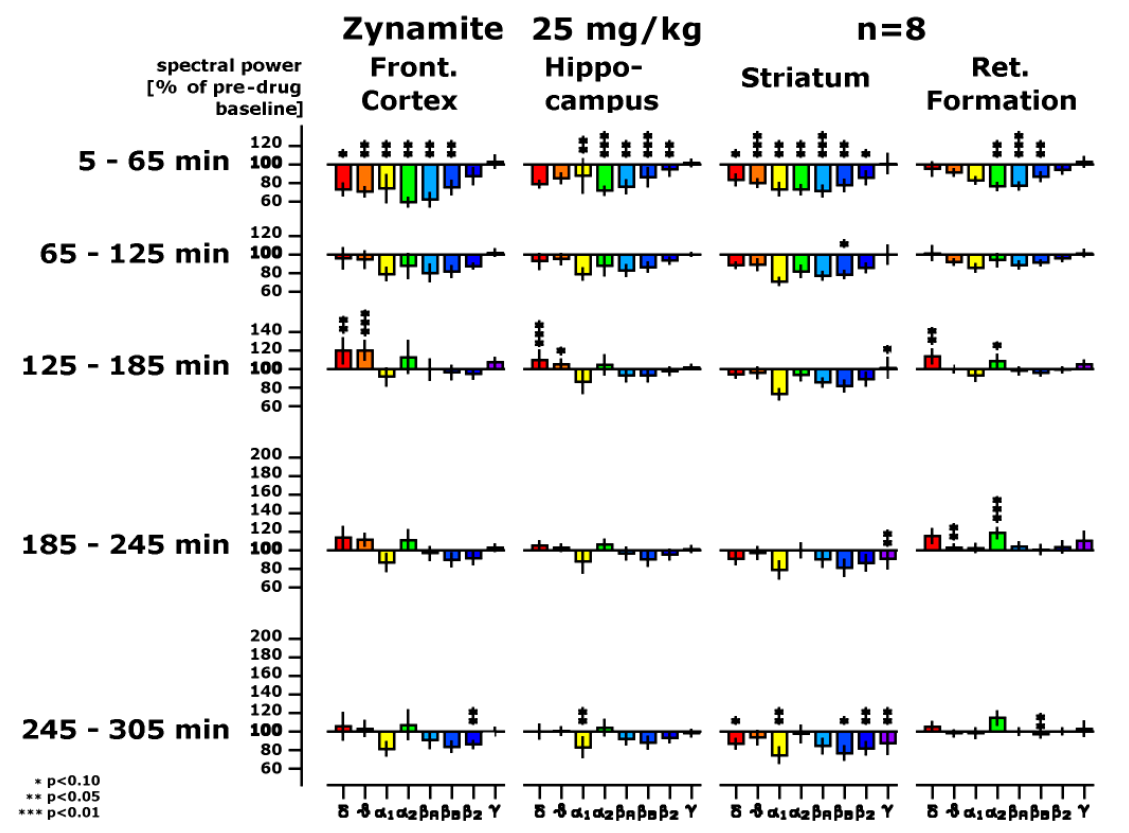

Figure 3. Frequency changes in the presence of $25 \mathrm{mg} / \mathrm{kg}$ Zynamite ${ }^{\circledast}$. Frequency ranges are depicted as coloured bar graphs on the abscissa representing delta (red), theta (orange), alpha1 (yellow), alpha2 (green), betala (light blue) and beta1b (dark blue) and gamma spectral power (violet) from left to right within the four brain areas as mentioned on top of the graph. Statistical significance in comparison to control (vehicle) is documented by stars: ${ }^{\star}=\mathrm{p}<0.10 ;^{\star *}=\mathrm{p}<0.05 ;{ }^{* *}=\mathrm{p}<0.01$. 
recognized. In the striatum a minor but statistically conspicuous decrease of delta waves was seen. From the second hour after administration on, increases of delta power emerged for the rest of the recording period in the frontal cortex and reticular formation. During the last hour increases of alpha2 power were observed except for the striatum. A whole time course is given in Figure 4.

Oral administration of the combination of Zynamite ${ }^{\oplus}(25 \mathrm{mg} / \mathrm{kg})+$ Caffeine $(0.25 \mathrm{mg} / \mathrm{kg})$ resulted in a statistically significant attenuation of all frequencies except for delta spectral power in comparison to placebo during the first hour after administration. Strongest attenuation was seen with respect to alphal and betal power in all brain regions. The alphal attenuation lasted into the second hour after administration, within the striatum into the last hour. During the third hour an increase of delta power emerged in the frontal cortex and hippocampus and somewhat less in the reticular formation. At the same time significant increases of alpha2 power were documented during the last 2 hours after administration. A total time course is given in Figure 5.

Oral administration of the mixture of Zynamite ${ }^{\circledast}(25 \mathrm{mg} / \mathrm{kg})$ with Caffeine $(0.50 \mathrm{mg} / \mathrm{kg})$ resulted in a statistically significant attenuation of spectral power with respect to all frequencies except for gamma power in comparison to placebo during the first two hours after administration. Effects were strongest in frontal cortex and hippocampus. The attenuation lasted until the third hour after administration, in the hippocampus and striatum until the end of the recording period. A total time course is given in Figure 6. When directly comparing the

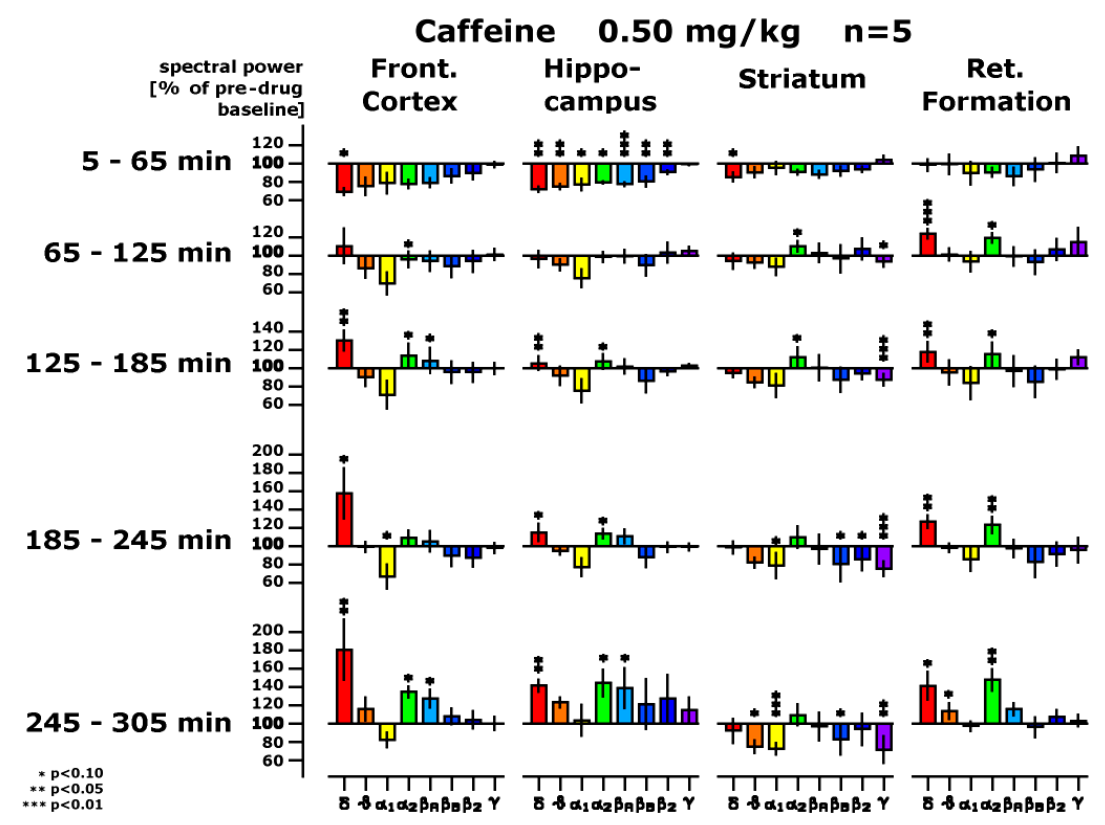

Figure 4. Frequency changes in the presence of $0.5 \mathrm{mg} / \mathrm{kg}$ caffeine. Frequency ranges are depicted as coloured bar graphs on the abscissa representing delta (red), theta (orange), alpha1 (yellow), alpha2 (green), betala (light blue) and betalb (dark blue) and gamma spectral power (violet) from left to right within the four brain areas as mentioned on top of the graph. Statistical significance in comparison to control (vehicle) is documented by stars: $^{\star}=\mathrm{p}<0.10 ;{ }^{\star *}=\mathrm{p}<0.05 ;{ }^{* *}=\mathrm{p}<0.01$. 


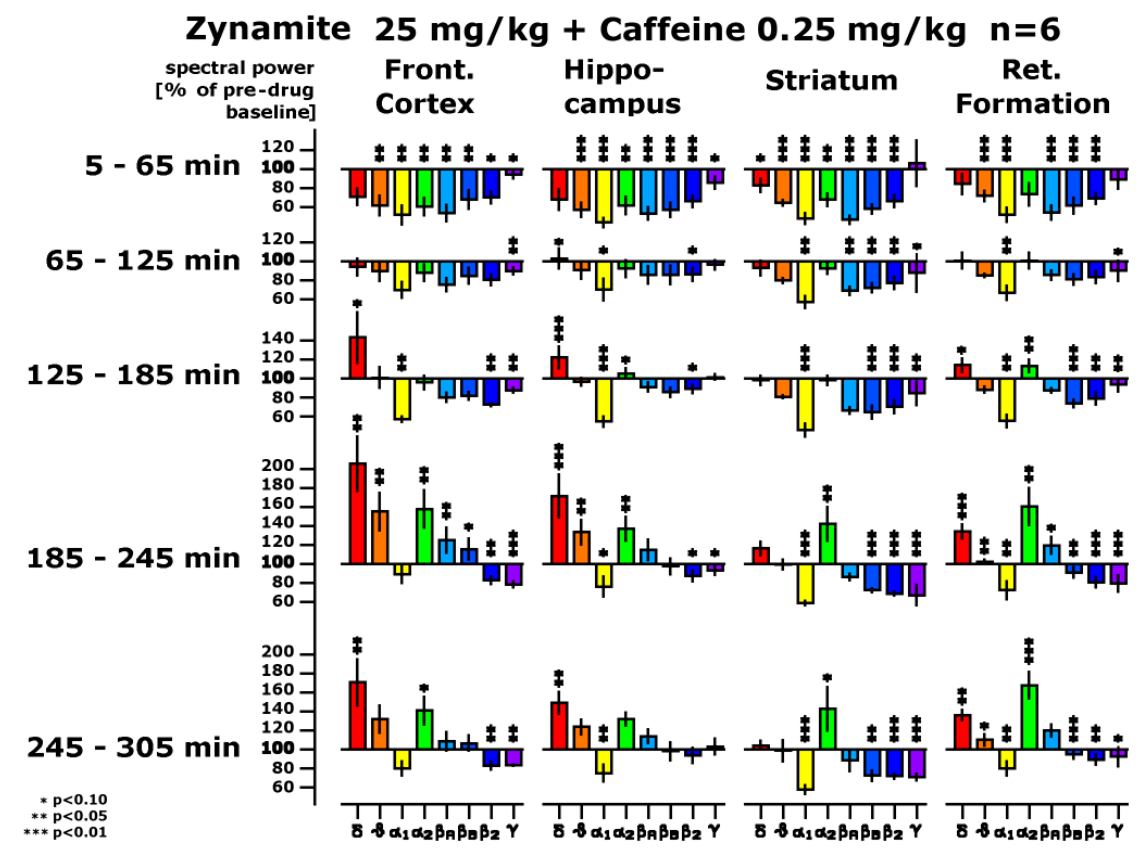

Figure 5. Frequency changes in the presence Zynamite ${ }^{\oplus}(25 \mathrm{mg} / \mathrm{kg})$ in combination with $0.25 \mathrm{mg} / \mathrm{kg}$ caffeine. Frequency ranges are depicted as coloured bar graphs on the abscissa representing delta (red), theta (orange), alpha1 (yellow), alpha2 (green), beta1a (light blue) and betalb (dark blue) and gamma spectral power (violet) from left to right within the four brain areas as mentioned on top of the graph. Statistical significance in comparison to control (vehicle) is documented by stars: ${ }^{\star}=\mathrm{p}<0.10$; $^{\star *}=\mathrm{p}<0.05$; $^{\star * \star}=\mathrm{p}<0.01$.

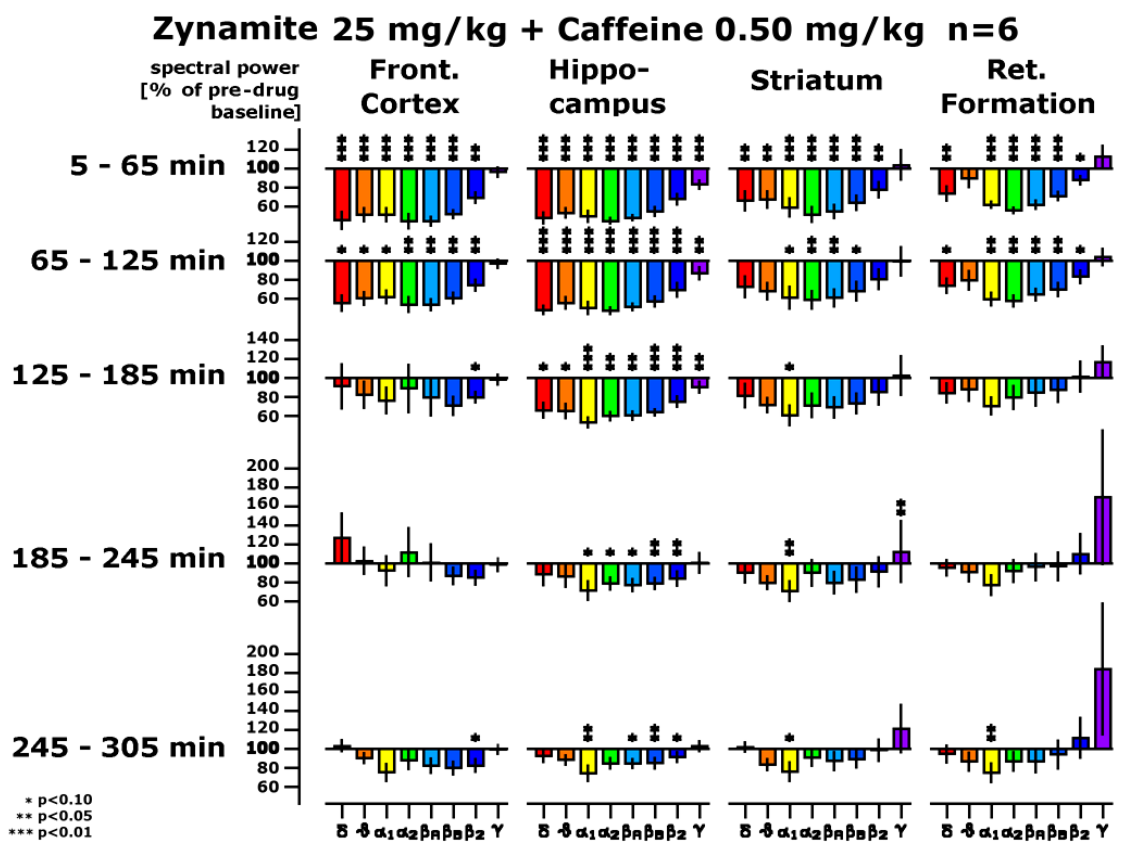

Figure 6. Frequency changes in the presence of Zynamite ${ }^{\circledast}(25 \mathrm{mg} / \mathrm{kg})$ in combination with $0.5 \mathrm{mg} / \mathrm{kg}$ caffeine. Frequency ranges are depicted as coloured bar graphs on the abscissa representing delta (red), theta (orange), alpha1 (yellow), alpha2 (green), beta1a (light blue) and betalb (dark blue) and gamma spectral power (violet) from left to right within the four brain areas as mentioned on top of the graph. Statistical significance in comparison to control (vehicle) is documented by stars: ${ }^{*}=\mathrm{p}<0.10$; $^{* *}=\mathrm{p}<0.05$; ${ }^{* *}=\mathrm{p}<0.01$. 
effects of Zynamite ${ }^{\varpi}$ and caffeine during the first hour after administration a close similarity between both becomes visible. Both combinations induce a much stronger attenuation of nearly all frequencies. Strongest difference to the mono-preparation consists in a large decrease of alphal spectral frequencies indicating a different mechanism of action (Figure 7). This alpha1 attenuation also dominates the effect of Zynamite ${ }^{\circledast}$ and caffeine during the second hour after administration. Likewise, the combination of Zynamite ${ }^{\varpi}$ with the low dose of caffeine shows a strong attenuation with respect to alphal waves (Figure 8). A massive attenuation of all frequencies is observed in the presence of the combination of Zynamite ${ }^{\otimes}(25 \mathrm{mg} / \mathrm{kg})$ with the higher dose of caffeine $(0.5 \mathrm{mg} / \mathrm{kg})$. This indicates a synergistic action, which can be demonstrated even more clearly when looking at the frequency changes in the hippocampus during the first 2 hours after administration (Figure 9).

A valuable methodology for comparison of frequency changes induced by different preparations has been described in numerous publications. Feeding all 24 variables ( 4 brain areas times 6 frequency ranges) into linear discriminant analysis the similarity of the action of Zynamite ${ }^{\oplus}$ and a low dose of caffeine is confirmed by projection of both in close neighborhood and showing the identical blue colour (Figure 10). The result of the combination is shifted more towards the plots for Paullinia and Methylphenidate indicating a different mechanism of

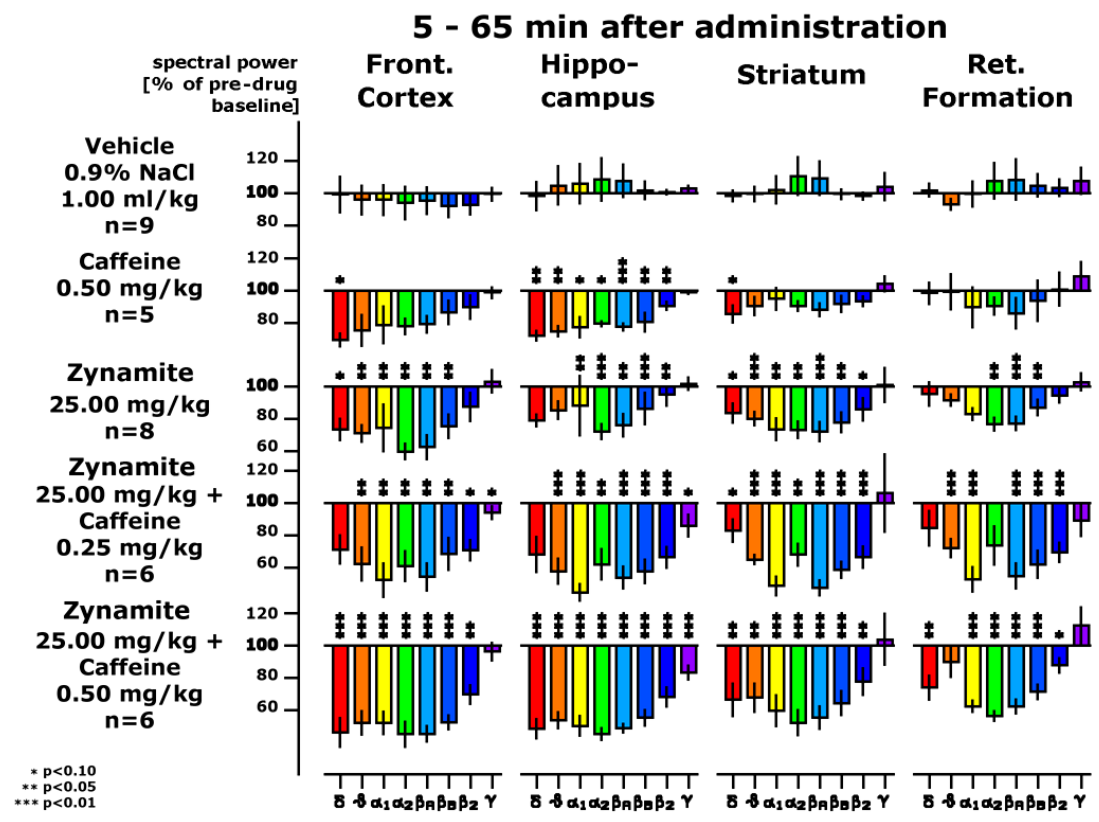

Figure 7. Direct comparison of the frequency changes observed in the presence of Zynamite ${ }^{\circledast}$ and caffeine alone and in the presence of the combinations during the first hour after administration. Frequency ranges are depicted as coloured bar graphs on the abscissa representing delta (red), theta (orange), alpha1 (yellow), alpha2 (green), betala (light blue) and betalb (dark blue) and gamma spectral power (violet) from left to right within the four brain areas as mentioned on top of the graph. Statistical significance in comparison to control (vehicle) is documented by stars: ${ }^{\star}=\mathrm{p}<0.10$; $^{\star *}=\mathrm{p}<0.05$; ${ }^{\star * \star}=\mathrm{p}<0.01$. Please note different scaling with respect to ordinate in comparison to previous images. 


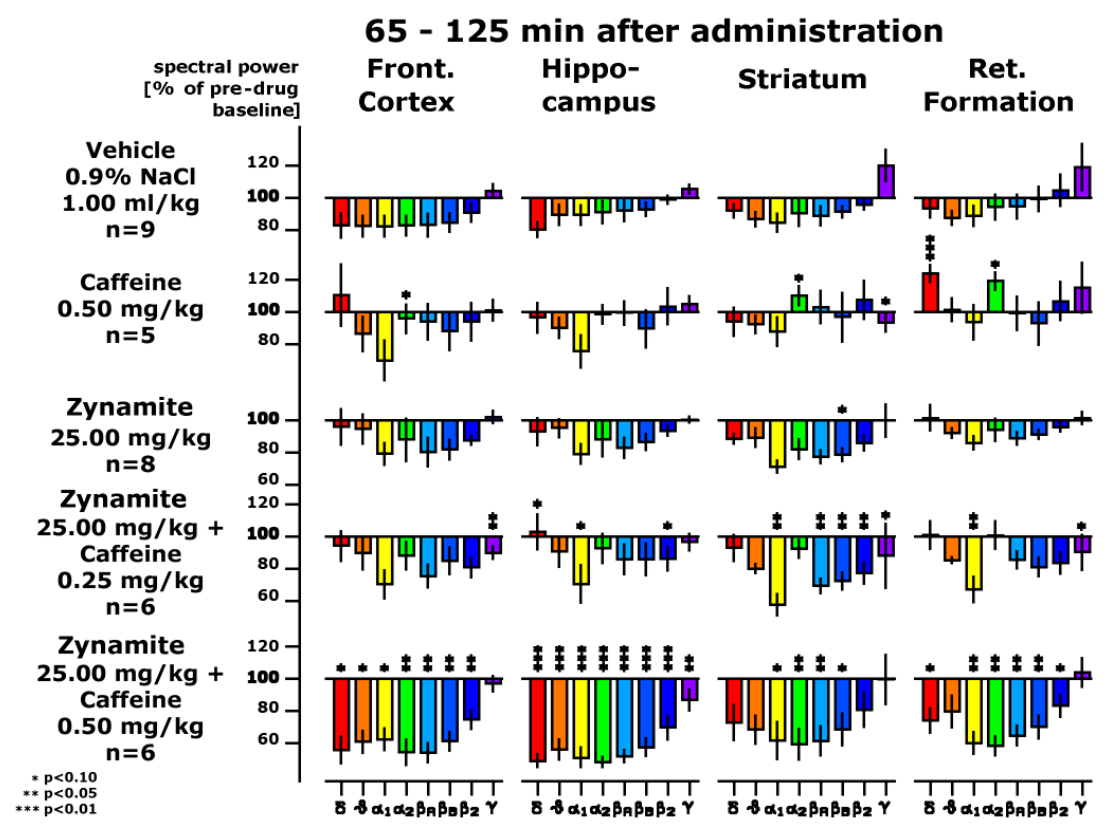

Figure 8. Direct comparison of the frequency changes observed in the presence of Zynamite $e^{\varpi}$ and caffeine alone and in the presence of the combinations during the second hour after administration. Frequency ranges are depicted as coloured bar graphs on the abscissa representing delta (red), theta (orange), alpha1 (yellow), alpha2 (green), beta1a (light blue) and beta1b (dark blue) and gamma spectral power (violet) from left to right within the four brain areas as mentioned on top of the graph. Statistical significance in comparison to control (vehicle) is documented by stars: ${ }^{*}=\mathrm{p}<0.10$; $^{\star *}=\mathrm{p}<0.05$; ${ }^{* *}=$ $\mathrm{p}<0.01$. Please note different scaling with respect to ordinate in comparison to previous images.

5 - 125 min after administration

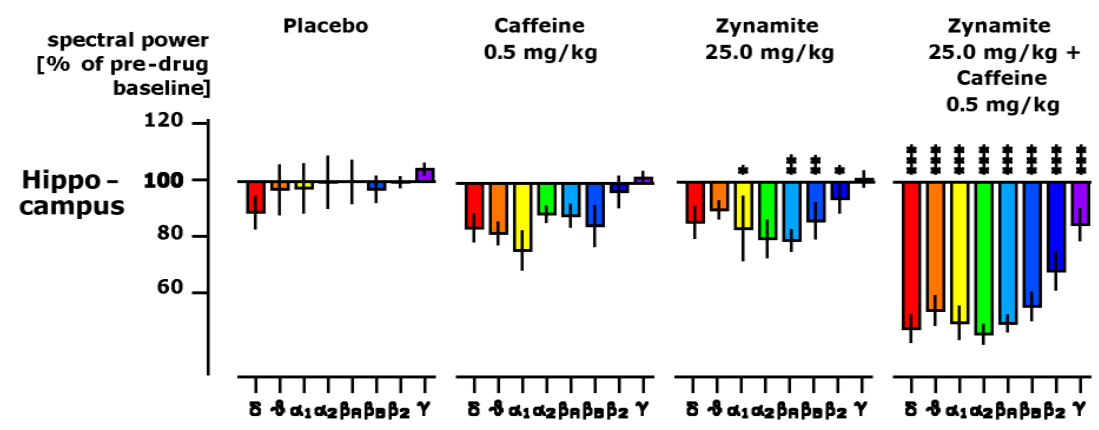

Figure 9. Documentation of synergy with respect to Caffeine and Zynamite ${ }^{\oplus}$ alone and their combination during the first two hours after administration in the hippocampus. Frequency ranges are depicted as coloured bar graphs on the abscissa representing delta (red), theta (orange), alpha1 (yellow), alpha2 (green), betala (light blue) and betalb (dark blue) and gamma spectral power (violet) from left to right within the four brain areas as mentioned on top of the graph. Statistical significance in comparison to control (vehicle) is documented by stars: ${ }^{*}=\mathrm{p}<0.10{ }^{* *}=\mathrm{p}<0.05$; $^{* *}=\mathrm{p}<0.01$. Please note different scaling with respect to ordinate in comparison to previous images.

action for the combination than for the mono-preparations. Details of administration of the preparation are listed in Table 2. 


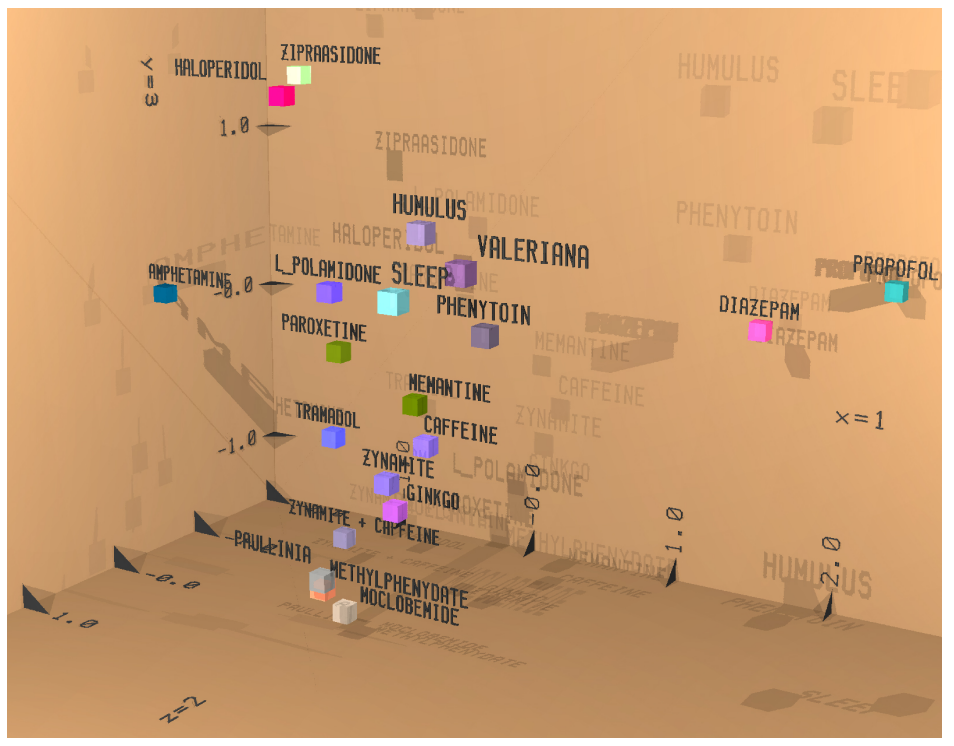

Figure 10. Documentation of the result of linear discriminant analysis of field potential data. Results of the first three discriminant functions are projected using spatial $x, y$ and $\mathrm{z}$-axis. Results from the next three functions are coded in colour using additive colour mixture according RGB like in TV.

Table 2. Listing of reference compounds documented in the discriminant analysis with respect to dosage and the type of administration. "i.p." = intraperitoneal administration.

\begin{tabular}{|c|c|c|c|c|c|c|c|}
\hline $\begin{array}{l}\text { Substance } \\
\text { Definition }\end{array}$ & $\begin{array}{c}\text { Dose } \\
{[\mathrm{mg} / \mathrm{kg}]}\end{array}$ & Application & Time & $\begin{array}{l}\text { Substance } \\
\text { Analysis }\end{array}$ & $\begin{array}{c}\text { Dose } \\
{[\mathrm{mg} / \mathrm{kg}]}\end{array}$ & Application & Time \\
\hline Diazepam & 0.50 & i.p. & $5-35 \mathrm{~min}$ & Ginkgo & 100.00 & orally & $\begin{array}{c}5-65 \\
\min \end{array}$ \\
\hline Memantine & 3.00 & i.p. & $5-35 \mathrm{~min}$ & Paullinia & 15.00 & orally & $\begin{array}{c}5-35 \\
\min \end{array}$ \\
\hline L-Polamidon & 1.00 & i.p. & $5-35 \min$ & Valeriana & 60.00 & orally & $\begin{array}{c}125-185 \\
\min \end{array}$ \\
\hline Ziprasidone & 1.00 & i.p. & $5-35 \min$ & Humulus & 50.00 & orally & $\begin{array}{c}125-185 \\
\min \end{array}$ \\
\hline Paroxetine & 1.00 & i.p. & $5-35 \mathrm{~min}$ & & & & \\
\hline $\begin{array}{c}(+) \\
\text { Amphetamine }\end{array}$ & 0.20 & i.p. & $5-35 \mathrm{~min}$ & & & & \\
\hline Propofol & 60.00 & i.p. & $5-65 \min$ & Zynamite & 25.00 & orally & $\begin{array}{l}5-65 \\
\min \end{array}$ \\
\hline Moclobemide & 5.00 & i.p. & $5-35 \mathrm{~min}$ & $\begin{array}{c}\text { Zynamite + } \\
\text { Caffeine }\end{array}$ & $\begin{array}{r}25.00 \\
+0.25\end{array}$ & orally & $\begin{array}{c}5-65 \\
\min \end{array}$ \\
\hline Tramadol & 5.00 & i.p. & $5-35 \min$ & & & & \\
\hline Methylpenidate & 2.50 & orally & $5-35 \mathrm{~min}$ & & & & \\
\hline Haloperidol & 0.50 & i.p. & $5-35 \mathrm{~min}$ & & & & \\
\hline Caffeine & 0.50 & orally & $5-65 \min$ & & & & \\
\hline Phenytoin & 4.00 & i.p. & $65-125 \mathrm{~min}$ & & & & \\
\hline Sleep & & & $65-125 \mathrm{~min}$ & & & & \\
\hline
\end{tabular}


Analysis of motion only revealed a statistically significant transient increase in the presence of the combination of Zynamite ${ }^{\varpi}$ with the lower dose of caffeine during the first hour. Caffeine alone and the combination of Zynamite ${ }^{\bowtie}$ with the higher dose of caffeine induced higher motion during the first hour after administration, but did not reach statistical significance (Table 3 ).

\subsection{Ex Vivo Analysis by Means of Hippocampus Slice Preparation}

Time courses of the recordings from the 4 animals revealed very stable results over 2 hours. Population spike amplitudes after administration of $0.5 \mathrm{mg} / \mathrm{kg}$ of caffeine revealed no difference to placebo during single shock stimulation (blue line in Figure 11), but revealed clearly higher amplitudes during theta burst stimulation (green line in Figure 11).

The daily administration of $25 \mathrm{mg} / \mathrm{kg}$ of Zynamite ${ }^{\bowtie}$ resulted in definitely higher amplitudes of the population spike already during single shock stimulation as documented in Figure 11. Theta burst stimulation induced not only massive higher amplitudes than after Placebo administration, but also clearly higher amplitudes in comparison to administration of caffeine (red line in Figure 11).

Finally, recording of population spike amplitudes after daily administration of the combination of $25 \mathrm{mg} / \mathrm{kg}$ Zynamite ${ }^{\varpi}$ with $0.5 \mathrm{mg} / \mathrm{kg}$ of caffeine revealed highest values during single shock stimulation as well during theta burst stimulation (dark blue line in Figure 11). The mean average values of three measurements (shadowed area in Figure 11) are documented with statistical significances in Figure 12.

Regarding now the numerical differences of the population spike amplitudes during single shock stimulation an over-additive effect becomes visible when comparing the effect of caffeine and Zynamite ${ }^{\varpi}$ alone with the combination. With respect to theta burst stimulation at least an additive effect is obvious (Table 4).

Table 3. Results of motion analysis.

\begin{tabular}{|c|c|c|c|c|}
\hline \multicolumn{5}{|c|}{ Motion $[\mathrm{cm} \mid \mathrm{h}]$} \\
\hline $\begin{array}{l}\text { Time } \\
\text { [min] }\end{array}$ & $\begin{array}{c}\text { Vehicle } \\
0.9 \% \mathrm{NaCl} \\
1 \mathrm{ml} / \mathrm{kg} \\
\mathrm{n}=9\end{array}$ & $\begin{array}{c}\text { Caffeine } \\
0.50 \mathrm{mg} / \mathrm{kg} \\
\mathrm{n}=5\end{array}$ & $\begin{array}{c}\text { Zynamite } 25.0 \mathrm{mg} / \mathrm{kg} \\
+ \text { Caffeine } 0.25 \mathrm{mg} / \mathrm{kg} \\
\mathrm{n}=6\end{array}$ & $\begin{array}{c}\text { Zynamite } 25.0 \mathrm{mg} / \mathrm{kg} \\
\text { + Caffeine } 0.50 \mathrm{mg} / \mathrm{kg} \\
\mathrm{n}=6\end{array}$ \\
\hline$-45-0$ & $626.67 \pm 120$ & $874.45 \pm 299$ & $854.52 \pm 142$ & $650.78 \pm 235$ \\
\hline $5-65$ & $676.49 \pm 117$ & $1049.00 \pm 112$ & $1170.00 \pm 160$ & $1060.00 \pm 239$ \\
\hline $65-125$ & $794.39 \pm 97$ & $798.41 \pm 83$ & $952.00 \pm 240$ & $994.55 \pm 218$ \\
\hline $125-185$ & $1051.10 \pm 81$ & $682.94 \pm 143$ & $677.73 \pm 128$ & $1040.00 \pm 205$ \\
\hline $185-245$ & $913.30 \pm 89$ & $843.34 \pm 154$ & $603.47 \pm 154$ & $847.19 \pm 198$ \\
\hline $245-305$ & $695.38 \pm 80$ & $629.49 \pm 115$ & $696.78 \pm 98$ & $870.84 \pm 224$ \\
\hline
\end{tabular}




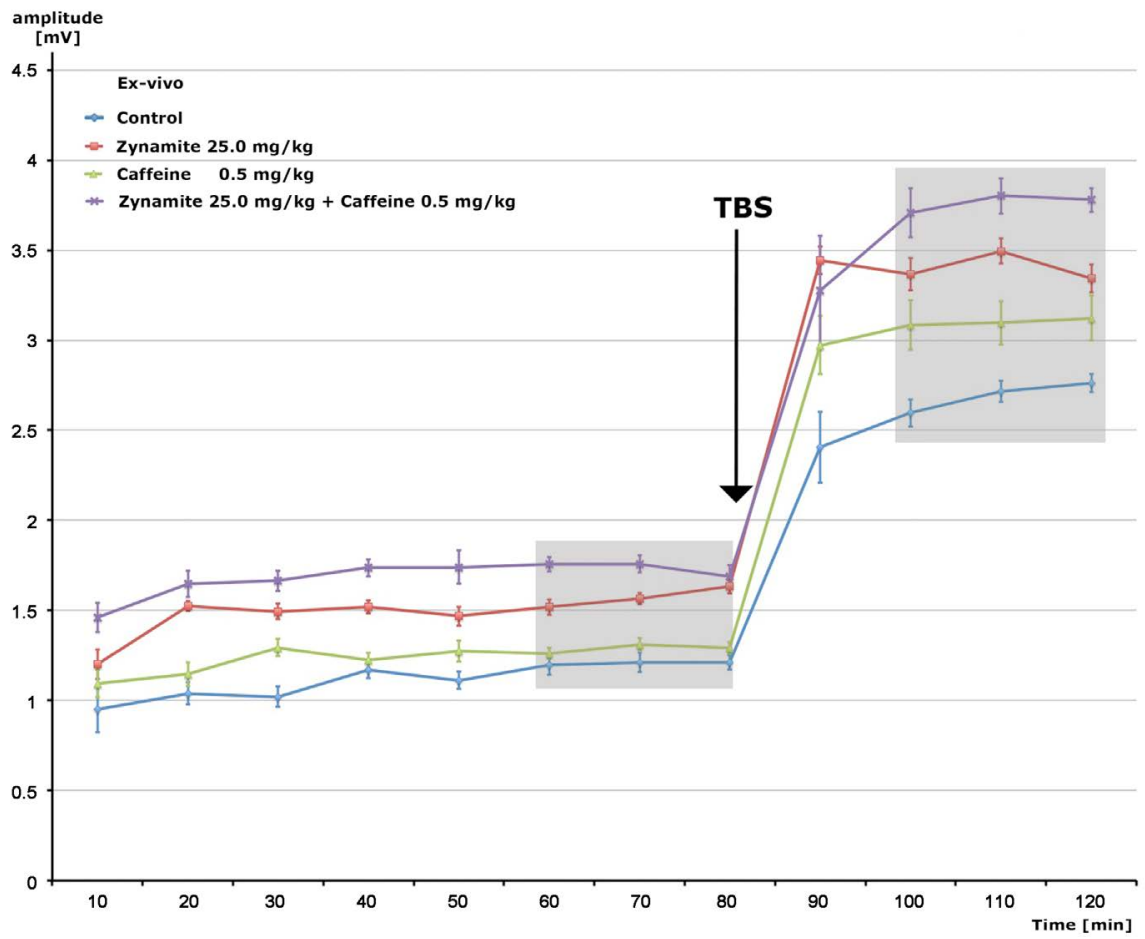

Figure 11. Time dependent effects of Control (Placebo), Caffeine $(0.5 \mathrm{mg} / \mathrm{kg}), Z_{\text {Znamite }}$ $(25.0 \mathrm{mg} / \mathrm{kg}$ ), and a combination of both (Zynamite $25.0 \mathrm{mg} / \mathrm{kg}+$ Caffeine $0.5 \mathrm{mg} / \mathrm{kg}$ ) on pyramidal cell activity in terms of changes of population spike amplitudes (as voltage on the ordinate). Results as obtained after performance of single stimuli (10 - $80 \mathrm{~min}$ ) or after burst stimuli (90 - $120 \mathrm{~min}$ ). Data are given as mean \pm S.E.M. of $\mathrm{n}=6$ slices from 1 animal. Values from shadowed areas are averaged to give one value as documented in Figure 12 .

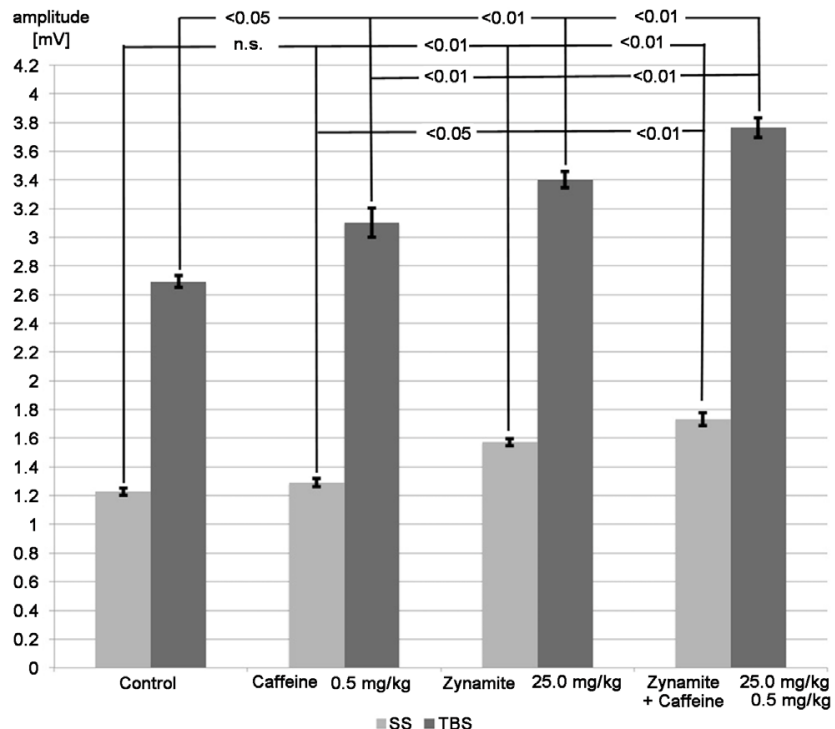

Figure 12. Effects of Control (Placebo), Caffeine $(0.5 \mathrm{mg} / \mathrm{kg})$, Zynamite $^{\circledast}(25.0 \mathrm{mg} / \mathrm{kg})$ and a combination of both (Zynamite $25.0 \mathrm{mg} / \mathrm{kg}+$ Caffeine $0.5 \mathrm{mg} / \mathrm{kg}$ ) on pyramidal cell activity in terms of changes of population spike amplitudes (as voltage on the ordinate). Results as obtained after performance of single stimuli (60 - $80 \mathrm{~min}$ ) or after burst stimuli (90 - $120 \mathrm{~min}$ ). Data are given as mean \pm S.E.M. of $\mathrm{n}=6$ slices from 1 animal. 
Table 4. Documentation of mean numeric differences between the 4 preparations in the presence of single stimuli and theta burst stimuli. Please note over-additive effect during single stimuli.

\begin{tabular}{ccccc}
\hline $\begin{array}{c}\text { Mean } \pm \text { SEM } \\
{[\mu \mathrm{V}]}\end{array}$ & $\begin{array}{c}\text { SS } \\
\mathbf{6 0}-\mathbf{8 0} \mathrm{min}\end{array}$ & $\begin{array}{c}\text { Diff. } \\
{[\mu \mathrm{V}]}\end{array}$ & $\begin{array}{c}\text { TBS } \\
\mathbf{1 0 0 - 1 2 0 \mathrm { min }}\end{array}$ & $\begin{array}{c}\text { Diff. } \\
{[\mu \mathrm{V}]}\end{array}$ \\
\hline Control & $-1226.48 \pm 23.85$ & & $-2691.17 \pm 39.78$ & \\
Caffeine $0.5 \mathrm{mg} / \mathrm{kg}$ & $-1289.17 \pm 27.43$ & 62.69 & $-3101.22 \pm 100.84$ & 410.05 \\
$\begin{array}{l}\text { Zynamite } 25.0 \mathrm{mg} / \mathrm{kg} \\
\text { Zynamite } 25.0 \mathrm{mg} / \mathrm{kg}\end{array}$ & $-1571.89 \pm 24.46$ & 345.41 & $-3401.67 \pm 57.47$ & 710.50 \\
+ Caffeine $\mathbf{0 . 5 \mathrm { mg } / \mathrm { kg }}$ & $-1733.72 \pm 46.30$ & 507.24 & $-3762.39 \pm 67.25$ & 1071.22 \\
\hline
\end{tabular}

\section{Discussion}

The animal model "Tele-Stereo-EEG" [2] has been used to characterize more than 200 preparations with respect to changes of the frequency content of field potentials recorded from different regions of the depth of the brain, namely frontal cortex, hippocampus, striatum and reticular formation. Feeding the data into linear discriminant analysis revealed that classical CNS-active drugs with well-established clinical indications group together according to the categories of clinical application [3].

The result of the present investigation revealed that the administration of $\mathrm{Zy}$ namite ${ }^{\oplus}$ or caffeine alone induced statistically significant attenuation of spectral power during the first hour after administration. In the presence of Zynamite predominantly alpha 2 and beta 1 spectral frequencies in all brain areas were attenuated. Exactly this pattern of frequency changes with respect to dominating attenuation of alpha2 and betal frequencies was observed after intraperitoneal injection of higher dosages of $1 \mathrm{mg} / \mathrm{kg}, 2.5 \mathrm{mg} / \mathrm{kg}$ or $5 \mathrm{mg} / \mathrm{kg}$ of caffeine [11]. Thus, there is a great similarity between the frequency changes induced by $\mathrm{Zy}-$ namite ${ }^{\oplus}$ with those seen in the presence of caffeine. Further, discriminant analysis confirms this similarity by projection the results of both preparations in close proximity to each other and showing identical colours, which points to a similar stimulant category of CNS activity.

Since it has been shown, that alpha2 waves are predominantly under the control of dopamine, activation of this neurotransmitter system might be responsible for the stimulating property of Zynamite ${ }^{\circledR}$. Beta1 waves seem to be regulated by the neurotransmitter glutamate [12]. Changes of the glutamatergic system are observed during performance of cognitive tasks. Interestingly, Mangiferin, the major bioactive ingredient in Zynamite ${ }^{\oplus}$ has been reported to improve long-term object memory in rats [13]. Bioavailability of Mangiferin has been shown to be increased after oral administration of a polyherbal preparation in comparison to administration of isolated pure Mangiferin, and that Mangiferin was bound to various tissues except for the brain [14]. This raises the question if Mangiferin alone is responsible for the activating effect of Zynamite ${ }^{\varpi}$ or if co-ingredients 
from the remaining $40 \%$ of the herbal formulation also contain pharmacologically active principles. The reproducible and stable attenuation of alpha1 spectral power during the rest of the recording time is interpreted as a higher state of wakefulness. Alpha1 waves are under the control of serotonin as reported earlier [15].

However, when Zynamite ${ }^{\varpi}$ was combined with very low doses of caffeine more than mere additive effects were observed. This can be recognized best by focusing on the frequency changes in the striatum and reticular formation (Figure 7). It is obviously that a potentiation mechanism has taken place. The same feature is observed when looking at the second hour after administration. In particular, when looking at the results obtained in the striatum and reticular formation, the highly significant attenuation of alphal waves cannot be explained by a simple additive effect. We emphasize that the combination of $\mathrm{Zy}$ namite $^{\circledast}$ with a dosage of caffeine fifty times lower results in a tremendous attenuation of all frequencies except for spectral gamma power in all brain regions beginning in the second hour after administration. Thus, if most caffeine is replaced by Zynamite ${ }^{\otimes}$ but at least $2 \%$ of caffeine is retained, this large increase in stimulation can be achieved.

The results of the field potential approach are corroborated by the results from the ex vivo trial using the hippocampus slice in vitro to follow excitability changes in the presence of $0.5 \mathrm{mg} / \mathrm{kg}$ of caffeine, $25 \mathrm{mg} / \mathrm{kg}$ of Zynamite ${ }^{\circledast}$ or their combination in comparison to Placebo after daily administration for one week. This approach was undertaken in order to demonstrate that CNS-active bioactive compounds from Zynamite ${ }^{\circledR}$ are able to pass the blood brain barrier and exert their action by changing the excitability state of the hippocampus after daily administration of the four preparations. The results are in favour of such an action since Zynamite ${ }^{\circledast}$ alone and in combination with caffeine induces increases of the amplitude of the population spike in the presence of single shock stimulation and theta burst stimulation, whereas caffeine alone only increases the population spike during theta burst stimulation leading to long-term potentiation. Long-term potentiation relates to space and time dependent memory [16]. From this it is evident, that caffeine as well as Zynamite ${ }^{\oplus}$ act in a similar way and have potential to improve cognitive functions. Based on the similarity of their action with respect to long-term potentiation, a replacement of caffeine by Zynamite ${ }^{\infty}$ makes sense.

\section{Conclusion}

In conclusion, in vivo administration of Zynamite ${ }^{\circledR}$ or caffeine displayed a similar action on the central nervous system with respect to changing the frequency pattern of brain regional field potentials and ex vivo by changing the excitability of the hippocampus of rats. A combination of both revealed over-additive or potentiating effects in both animal models pointing to a synergy between Zynamite $^{\oplus}$ and caffeine. Zynamite ${ }^{\bullet}$ has potential as a CNS-activating nutraceutical that could be used to replace caffeine. 


\section{Acknowledgements}

Mrs. Ingrid K. Keplinger-Dimpfel and Mrs. Chiegoua Dipah Gwladys Nina are thanked for performing quality control critically proof reading of the manuscript.

\section{Conflict of Interest}

The study was financially supported by Nektium S.L., Las Palmas, Gran Canaria. Drs. Nigel Gericke and Julia Wiebe are employed by Nektium Pharma and had no role in the conduct of the experimental work or analysis of the results.

\section{References}

[1] Shah, K.A., Patel, M.B., Patel, R.J. and Parmar, P.K. (2010) Mangifera indica (Mango). Pharmacognosy Reviews, 4, 42-48. https://doi.org/10.4103/0973-7847.65325

[2] Dimpfel, W., Spüler, M. and Nickel, B. (1986) Radioelectroencephalography (Tele-Stereo-EEG) in the Rat as a Pharmacological Model to Differentiate the Central Action of Flupirtine from That of Opiates, Diazepam and Phenobarbital. Neuropsychobiology, 16, 163-168. https://doi.org/10.1159/000118319

[3] Dimpfel, W. (2003) Preclinical Database of Pharmaco-Specific rat EEG Fingerprints (Tele-Stereo-EEG). European Journal of Medical Research, 8,199-207.

[4] Dimpfel, W. (2013) Pharmacological Classification of Herbal Extracts by Means of Comparison to Spectral EEG Signatures Induced by Synthetic Drugs in the Freely Moving Rat. Journal of Ethnopharmacology, 149, 583-589. https://doi.org/10.1016/j.jep.2013.07.029

[5] Lynch, G. and Schubert, P. (1980) The Use of in-Vitro Brain Slices for Multidisciplnary Studies of Synaptic Function. Annual Review of Neuroscience, 3, 1-22. https://doi.org/10.1146/annurev.ne.03.030180.000245

[6] Dingledine, R. (1984) Brain Slices. Plenum Press, New York, London. https://doi.org/10.1007/978-1-4684-4583-1

[7] Dimpfel, W. (1996) Effect of Thioctic Acid on Pyramidal Cell Responses in the Rat Hippocampus in Vitro. European Journal of Medical Research, 1, 523-527.

[8] Dimpfel, W. and Biller, A. (2015) Mechanism of Action of Low Dose Preparations of Coffea Arabica, Gelsemium and Veratrum Based on in Vivo and in Vitro Neurophysiological Findings. Journal of Behavioral and Brain Science, 5, 368-380. https://doi.org/10.4236/jbbs.2015.59036

[9] Haas, H.L., Schaerer, B. and Vosmansky, M. (1979) A Simple Perfusion Chamber for the Study of Nervous Tissue Slices in Vitro. Journal of Neuroscience Methods, 1 , 323-325. https://doi.org/10.1016/0165-0270(79)90021-9

[10] Schiff, S.J. and Somjen, G.G. (1985) The Effects of Temperature on Synaptic Transmission in Hippocampal Tissue Slices. Brain Research, 345, 279-284. https://doi.org/10.1016/0006-8993(85)91004-2

[11] Dimpfel, W., Schombert, L., Vega-Morales, T. and Wiebe, J. (2016) Neuropharmacological Characterization of Extracts from Rhodiolarosea, Oenotheraparadoxa and Paulliniacupana in Comparison to Caffeine. Pharmacology \& Pharmacy, 7, 290-303. https://doi.org/10.4236/pp.2016.77036

[12] Dimpfel, W. (2015) Drug Discovery and Translational Medicine Based on Neurophysiological Techniques. A Holistic Approach to Saving Animals. Books on Demand, Norderstedt. 
[13] Pardo Andreu, G.L., Maurmann, N., Reolon, G.K., De Farias, C.B., Schwartsmann, G., Delgado, R. and Roesler, R. (2010) Mangiferin, a Naturally Occurring Glucoxilxanthone Improves Long-Term Object Recognition Memory in Rats. European Journal of Pharmacology, 635, 124-128. https://doi.org/10.1016/j.ejphar.2010.03.011

[14] Kamalla, A.K., Ramasamy, M.K., Inampudi, R.J., Dubey, G.P., Agrawal, A. and Kalliapan, I. (2015) Comparative Pharmacokinetic Study of Mangiferin after Oral Administration of Pure Mangiferin and US Patented Polyherbal Formulation to Rats. AAPS PharmSciTech, 16, 250-8. https://doi.org/10.1208/s12249-014-0206-8

[15] Dimpfel, W. (2007) Characterization of Atypical Antipsychotic Drugs by a Late Decrease of Striatal Alphal Spectral Power in the Electropharmacogram of Freely Moving Rats. British Journal of Pharmacology, 152, 538-548.

https://doi.org/10.1038/sj.bjp.0707427

[16] Cortese, G.P., Olin, A., O’Riordan, K., Hullinger, R. and Burger, C. (2018) Environmental Enrichment Improves Hippocampal Function in Aged Rats by Enhancing Learning and Memory, LTP, and mGluR5-Homer1c Activity. Neurobiology of Aging, 63, 1-11. https://doi.org/10.1016/j.neurobiolaging.2017.11.004 